\title{
The Prison Media Complex: Labour, Technology and Communication Infrastructures in the Prison System
}

\author{
Fredrik Stiernstedt* and Anne Kaun** \\ *Södertörn University, Stockholm, Sweden, fredrik.stiernstedt@sh.se, \\ www.sh.se/mkv
}

**Södertörn University, Stockholm, Sweden, anne.kaun@sh.se, www.annekaun.com

\begin{abstract}
Prisons are a recurring topic and backdrop in the popular culture of the Global North. They often serve as spectacular environments that seem far removed from most people's everyday lives. This article develops the notion of the prison media complex and discusses material entanglements between prisons and private media industries via the production of media technologies, consumption of communication, and technology development in the prison sector. The article seeks to answer the question of how we can conceptualise the prison media complex (PMC) from a materialist perspective. Taking the Swedish context as a starting point, we analyse the economic and material connections that characterise the PMC in this national context. Drawing on archival data, participant observations at prison technology tradeshows and a prison sector conference, as well as freedom of information requests, we bring nuance to the picture of media and communication technologies, as technologies of freedom are also based on unfreedom and captivity.
\end{abstract}

Keywords: prison; prison media; prison media complex; technologies of freedom; prison labour; communication infrastructures; political economy of the media

Acknowledgement: We would like to thank the reviewers and the editor of tripleC for their constructive feedback that helped to considerably improve the article.

\section{Introduction}

Crime and punishment are integral parts of the media spectacle (Barton and Brown 2015): films, television series, podcasts, books and plays on this topic constitute an ever-growing part of the media landscape. The demand for content on law and order in courts and prisons seems infinite (Cheliotis 2010; Fiddler 2011). This media spectacle of crime and punishment, including the representation of prisons and the incarcerated, has been addressed in several studies linking the demand for prison-related content to an increasing entanglement of the logic of the cultural industries with the logic of punishment. This is what Page and Ouellette (2020) called the "prison-televisual complex", and Brown (2009) has addressed as the "culture of punishment". These writings focus on the importance of prisons for media production at the symbolic level.

The relationship between the penal system and the media in its material and industrial dimensions has been less explored. This article seeks to remedy this lack via an analysis of what we call the prison media complex (PMC). The article addresses the following main research question: How can we conceptualise the prison media complex (PMC) from a materialist perspective? We introduce the notion of the PMC to describe and analyse the growing entanglement of private companies and the prison sector, focusing on media technologies beyond the symbolic production of prison- 
related media content. The concept of a complex implies both institutional and informal bonds between the media and communication industry and the penal system.

Our understanding of materialism relates here to the question of the political economy of the media and communication industries (Fuchs and Mosco 2015). We are interested in the prison work that emerges in relation to the media and communication industry. We explore prison media work as necessary for cultural production.

The PMC is characterised by three main aspects:

1. Media technologies and infrastructures have been constructed, built and maintained in prisons by the labour of incarcerated individuals (Kaun and Stiernstedt 2020a);

2. The prison system is deeply intertwined with the media and communication industry as suppliers of technologies for surveillance and control prisons (Kaun and Stiernstedt 2020b);

3. Prisons serve as testbed environments for developing new media technologies (Kaun and Stiernstedt 2021).

In this sense, prisons are producers and consumers of media technologies. However, the entanglement of prison and industrial production is not new. It has a history rooted in the 19th and early 20th centuries, where incarcerated labour played an essential role in constructing communication infrastructure, such as digging canals and putting up poles and cables for electronic telegraphy (von Hofer 1993). Since the 1970s, this connection has grown stronger and has become more globalised, mirroring other tendencies in the overall economy.

By focusing on the relationship between the media and communication industry and prisons from a material rather than a symbolic perspective captured by, for example, the notion of the prison-televisual complex (Page and Ouellette 2020), this article extends previous knowledge by demonstrating the importance of prisons for media technology industries. This approach casts new light on media history, as it reveals that media that de Sola Pool (1983) famously called "technologies of freedom" rest on the logics of captivity: that is, the production of media and communication technologies under conditions of incarceration. In the following two sections, we first use Swedish data as our main example to give a historical account of the relationship between the media industry and the prison industry; secondly, we discuss the contemporary intersections between media, communication and penal institutions, drawing on material from Sweden and the Swedish Prison and Probation Service, international trade fairs and other forms of global cooperation between prison systems; and thirdly, we develop three avenues of the PMC, namely the production, consumption and testing of communication technologies. We conclude by linking back to the question of what it means that technologies of freedom are produced in the context of captivity and incarceration.

\section{From the Prison Industrial Complex to the Prison Media Complex}

The term "prison industrial complex" (PIC) was first used by social theorist Mike Davis (1995), later picked up by journalist Erik Schlosser (1998) and further developed by Angela Davis (2003). This term is modelled on the notion of the "military-industrial complex" (MIC), as underlined by Davis (2003). Both the MIC and the PIC emphasise that the entanglement of industries, the penal regime and the military complex always also produces "social destruction", linking carceral and warfare logics with value production (see also Page and Ouellette 2020). Both terms hence describe the "complex configuration" of the prison system, multinational businesses, and the inmate 
population in the political economy of the 21st century (Smith and Hattery 2006), connecting this to welfare retrenchment, racism, and the criminalisation of marginalised groups (Brewer and Heitzeg 2008; Davis 2000; Smith and Hattery 2010; Wehr and Aseltine 2013).

Much scholarly writing has not only analysed but also problematised, critiqued and described alternatives to this political-economic penal configuration (e.g. Hartnett 2011; PCARE 2007; 2017). The highlighting of the interconnections between private companies and the prison system has gained importance with the rapid expansion of the prison population. During the last 40 years, the global prison population has grown exponentially in many countries, especially in the US and in other countries with partly privatised prison systems such as the United Kingdom (Blumstein 2011). Consequently, the period from the 1980s until today has been described as an era of mass incarceration (Wacquant 2002). In the US alone, the number of those incarcerated for drug offences skyrocketed from 40,900 in 1980 to 430,926 in 2014. ${ }^{1}$ This global development follows patterns of structural injustices of race, gender and class, in which policing, control and criminalisation have mainly affected marginalised groups in many parts of the world (Sudbury 2014). The US is by far the world leader in incarceration, with 698 imprisoned citizens per 100,000 in 2019 (Sawyer and Wagner 2020), and with a significant representation of incarcerated individuals being people of colour. According to the Sentencing Project, male people of colour are six times likelier to be incarcerated than white men. ${ }^{2}$ Similarly, David Scott points out that African Americans only comprise 13 percent of the total US population but comprise 60 percent of the prison population (Scott 2013, quoted in Mathiesen 2014, 3).

This era of mass incarceration has both political-economic and ideological explanations. The end of a Keynesian paradigm in the global economy and the triumph of neoliberal economics has precipitated a global spike in unemployment rates. The prison functions as a social institution that absorbs negative externalities (i.e. social costs of market fluctuations in the economic system); thus, as Rusche and Kirchheimer (1939/2009) showed as early as the 1930s, unemployment rates correlate directly with the size of incarcerated populations (for an updated discussion and reanalysis of the original argument by Rusche and Kirchheimer, see Inverarity and McCarthy 1988).

An ideological shift has contributed to rising prison populations, accompanying the economic developments, as political agendas claiming to be tough on crime have been winning ground since the 1980s; this has tilted the debate on the penal system in favour of longer sentences, criminalisation of a broader range of behaviour, and more incarceration as a punishment for petty crimes than ever before. Here, the media has played a key role in "reinforcing the legitimacy of mass incarceration as a remedy for social deviance" (Novek 2009, 377; see also Yousman 2009). The so-called 'war on drugs' emerging in the US in the 1980s and 90s (but with local versions in many countries) has also contributed to increased incarceration by expanding the list of illegal offences and increasing racial profiling (Blumstein 2011). These developments have resulted in the increased privatisation of the prison system in many parts of the world. This increased privatisation may have had at least some effect on incarceration rates, even if this is a disputed issue (see e.g. Mathiesen 2014; Gilmore 2007).

It is not only private prisons that contribute to the commercialisation of the prison system. Commercialisation is a broader process that also exists in countries without

${ }^{1}$ Sentencing Project. https://www.sentencingproject.org/criminal-justice-facts/ (accessed 19 October 2021).

${ }^{2}$ Sentencing Project. https://www.sentencingproject.org/criminal-justice-facts/ (accessed 19 October 2021). 
private prisons. Private or commercial prisons are increasing incentives for criminalising more behaviours and growing the prison population. At the same time, public prisons are commercialised through prison labour: making a profit on unpaid/underpaid labour (Thompson 2012) and using advanced technological solutions to guard and manage a prison population to minimise the cost of salaries for human guards (as for "prisons without guards"; Delgoda 1980). Regarding the different aspects of commercialisation, the notion of a PIC has been developed. The PIC is defined as an interweaving of private business and government interests with the dual purposes of profit and social control (Goldberg and Evans 2009). The definition of the PIC, then, following the neighbouring concept of a MIC, includes cooperation between state and commercial enterprises that includes both institutionalised and informal relations.

The PIC and the MIC are not only structurally similar or neighbouring concepts but also overlap to some extent, as, for example, security solutions and communication and technology companies are often involved simultaneously in the military and penal industries. One example of this in the Swedish context is the public tech company Telub, which started in 1964 as a branch within the Swedish military and was also responsible for developing and delivering CCTV systems and other telecommunications-based surveillance technologies to the Swedish Prison and Probation Services in the 1960s and 1970s.

The PIC and the MIC also mirror political and business interests, and as such, they shed light on the entire economic system. As discussed by Goldberg and Evans (2009), communication and media companies are an important part of the PIC; however, their roles and importance have been given insufficient attention in previous research, both within penology and within media studies. The current article turns attention towards this aspect of the PIC, namely the role of communication and media companies that constitute the PMC.

Herbert Schiller and Joseph Dexter Phillips (1970) argue that technology development takes place within complexes: that is, institutional constructions of both a material and a conceptual nature that combine different interests to meet a common goal. Schiller refers to communication complexes, military complexes and electro-industrial complexes. Companies and institutions that form these formal and informal network relations share common goals. Similarly, Page and Ouellette (2020) observe an increasingly close entanglement between cultural industries and the penal system. Analysing the TV programme 60 Days In, a popular reality show that follows law-abiding citizens placed in jails, Page and Oullette argue that this show is an example of how penal logic has become implicated in the business and cultural practices of entertainment, while the logic of the cultural industries, including quantifications of the attention economy through ratings, profitability and so on, have entered the prison system.

While Schiller and Phillips (1970) are interested in the material preconditions for media technological development, Page and Ouellette focus mainly on the implications of symbolic production in the prison context. Adding to and extending the discussion developed by Page and Ouellette, we focus on material aspects - namely, specific companies and technology developments constitutive of the PMC - as we see them. Accordingly, we conceive the PMC is a subcategory of the PIC, with a broader scope than the prison-televisual complex proposed by Page and Ouellette.

While the notion of the prison-industrial complex has primarily been developed within the US context, we argue that it can be similarly applied to other economic and penal contexts, as it mainly aims to identify the intricate, formal and informal links between different sectors to further value production. The objective of this article is to examine the nature of these relations and how they play out in the Swedish prison 
context while making international connections. The Swedish and Scandinavian penal institutions are often seen as international outliers, described in terms of Scandinavian exceptionalism, especially concerning the (exceptionally low) proportion of the population who are incarcerated and the and the (exceptionally humane) treatment of prisoners (Pratt 2008).

Scandinavian exceptionalism has been both challenged (Scharff Smith 2012) and defended (Pratt and Eriksson 2012). For the scope of our project, we argue that the PMC is less exceptional in Scandinavian countries compared to other aspects of the prison system. Relationships between the media and communication industry, the state and the prison system share many similarities worldwide, although the scale of these relationships naturally differ (Sweden has a much more limited PMC than do larger countries with a higher incarcerated percentage). Sweden, however, shares the international trend of the so-called "punitive turn" that has been identified since the 1980s (Brown 2009). Prison populations have been growing, and the ideology and rhetoric surrounding crime and punishment have been increasingly marked by notions of harsher punishments and more policing and surveillance. This punitive turn and mass incarceration have increased the attractiveness of this sector for private businesses. There are, however, context-specific developments in Sweden that have cleared the way for the emergence of a PMC, particularly in the expansion of the public sector up to the 1970s and the increasing commercialisation and privatisation that followed.

\section{Disentangling the Prison Media Complex}

This article uses archival data and document analysis to present an account of the institutionalised and informal relations between the media and communication industry and the corrections sector (i.e. the PMC). The materials analysed include archival sources documenting the Swedish Prison and Probation Services (e.g. client registers, official statistics published by the Prison and Probation Services, and reports and concept papers by the board of Prison and Probation Service, including annual reports from 1970 to 2000).

Although much of the material we rely on originates from the Swedish penal system, the PMC also has international layers, including transnational, globally active companies and actors that dominate the prison tech sector (Kaun and Stiernstedt 2021). At the same time, the possibility of establishing close connections between prison facilities and private companies is strongly dependent on national jurisdictions and regulations and local regulations that might vary from facility to facility.

Figure 1 illustrates the different layers of the PMC in which connections between media and communication companies and the corrections sector emerge. On the local level, smaller companies, for example, rely on prison labour to produce specific products. Connections often emerge via personal contacts between work operation officers at facilities and local companies. At the national level, specific regulations potentially constrain or foster collaboration with private companies and the corrections sector. The international layer of the PMC emerges via global companies that, for example, deliver infrastructure and technological solutions to the corrections sector.

Capturing the contours of the PMC entails the inclusion of international connections and networks in the analysis. Collaborations between national public enterprises (in the Swedish case, the Prison and Probation Service) and multinational tech companies and collaborations between prison and probation services in different countries are important aspects of the PMC. Therefore, we conducted participant observations at two security-technology fairs, one in the United Kingdom and the other in the US, 
exclusively or partly catering to the corrections sector. At the fairs, we collected information from technology companies active in the corrections sector by interviewing sales managers and collecting information materials provided at exhibition stalls. We also attended the European conference "Technology in Corrections", held in Lisbon in April 2019. The intersectoral meeting is jointly organised by the European Organisation of Prison and Correctional Services (EuroPris) and the International Corrections and Prisons Association (ICPA) and brings together practitioners from the corrections sector, industry representatives and academics. The participant observations during the conference were documented in extensive field notes, including PowerPoint presentations, which were made freely available after the conference.

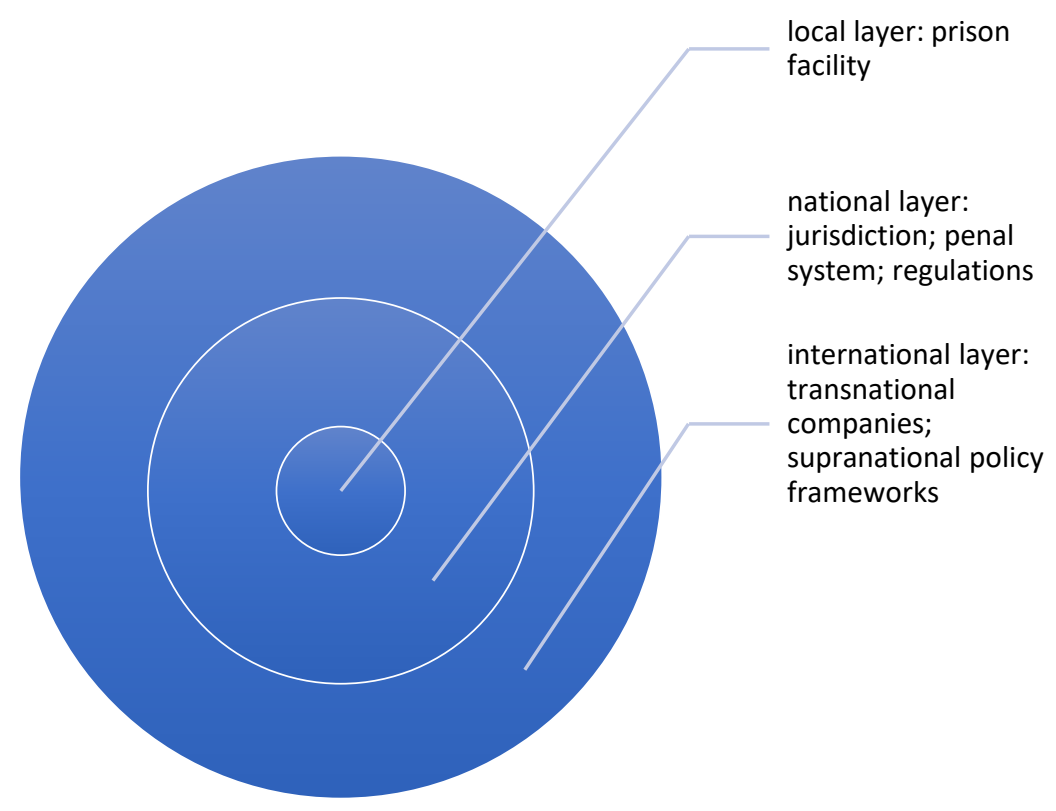

Figure 1. Layers of the prison media complex

\section{Three Avenues of the Prison Media Complex}

While Schiller and Phillips (1970) analyse complexes of communication in terms of formal and informal relationships between different actors that have an interest in specific technological developments and hence form complexes, we considered the PMC in terms of entanglements in production, consumption and development based on previous definitions of the PIC. As previously outlined, the PIC is characterised by

1) increased incentives for criminalising more behaviours and growing the prison population (i.e., an inmate is a valuable commodity), leading to an increase in the consumption of security products by prisons,

2) industrial prison production contributing to profit from unpaid/underpaid labour,

3) using advanced technological solutions to guard, categorise and manage a prison population to minimise the costs of salaries for human guards ("prisons without guards") and testbedding novel technologies in the prison context.

In the following section, we further develop the three avenues of the PMC (i.e. media technology production, media technology consumption and media technology 
development) by focusing on institutional and informal relationships between state agents (e.g. prison facilities, prison authorities and politicians) and media and communications industries. First, we discuss the role of prison labour in the construction and maintenance of media and communication infrastructures. We then consider the roles played by media and communication technologies (and the companies behind them) and prisons to investigate the ties between the communication and the correction industry. Finally, we focus specifically on the most recent decades of digitisation and the idea of so-called "smart prisons" (Kaun and Stiernstedt 2020b).

\subsection{Production: Prison Media Work}

The construction of infrastructure such as the railway and canal systems has relied to a large extent and in many national contexts on incarcerated labour (Mancini 1996). This was mainly contracted work or the so-called leasing of prisoners' labour for actors external to the prison facilities. Yet prison labour often remains invisible to the broader public, even if carried out in plain sight (Feldman 2020). What is also less known is that prison labour has been essential for constructing modern infrastructure for media and communication in the post-war period. Telephone systems, computer hardware, display media (e.g. newspaper stands and billboards) and technologies for media distribution have all been produced in part by incarcerated labour (Kaun and Stiernstedt 2020a). The extent to which prison labour has had importance for the media and communication industry varies between different periods and places, but the relationship between the media and communication industry and prison labour exists in most modern prison systems.

The roles that prison labour has had for the media and communication industry is, from an overall and general perspective, rather limited, even though it has formed a substantial part of the industrial production in Swedish prisons, with about 10 percent of total industrial production taking place in Swedish industrial prisons (Kaun and Stiernstedt 2020a). Prison labour has had, and still has, significance for specific products of the media and communication industry that require low-skilled routine labour and that need to be relatively cheap. This mainly pertains to hardware and technology (e.g. cables, poles and packaging) rather than media content or texts, although it is common for prison interiors and prison clothing used as costumes for TV or film productions to be made by prisoners in prison workshops. Even if the Swedish Prison and Probation Service itself states that it never competes with commercial enterprises by using low prices, and even though it is prohibited by Swedish law to compete with commercial companies through that means, questions of unfair competition and pricing issues have constantly been raised about prison labour throughout the twentieth century. 


\begin{tabular}{|l|l|c|}
\hline Company & Commodity & Production Value in SEK \\
\hline Nyckelhus AB & Ready-built houses & $20,900,000$ \\
\hline Sweden's Military & Equipment & $7,850,000$ \\
\hline Swedish Royal Mail & Equipment & $6,400,000$ \\
\hline IKEA & Furniture & $4,000,000$ \\
\hline Road Administration & Road signs & $3,000,000$ \\
\hline Gothenburg Municipality & Laundry service & $2,900,000$ \\
\hline $\begin{array}{l}\text { Televerket } \\
\text { (a public enterprise for tele- } \\
\text { communications) }\end{array}$ & Equipment & $2,790,000$ \\
\hline Trästandard & Furniture & $1,800,000$ \\
\hline Public agencies & Furniture & $1,100,000$ \\
\hline KF & Furniture & $1,000,000$ \\
\hline
\end{tabular}

Table 1: The largest clients of the Prison and Probation Service in 1976 (Expressen, 6 November 1976)

\begin{tabular}{|c|c|}
\hline Company & Area of Business \\
\hline Aftonbladet & Journalism \\
\hline Brand New Television AB & Media production \\
\hline Canon & Electronics \\
\hline Dagens Nyheter & Journalism \\
\hline Duplica Print \& Kommunikation & Advertising \\
\hline EO Grafiska & Graphic design \\
\hline Eskilstuna-Kuriren & Journalism \\
\hline Esselte & Graphic design \\
\hline Exakta Printing $A B$ & Advertising \\
\hline Expressen & Journalism \\
\hline Göteborgsposten & Journalism \\
\hline Svenska Dagbladet & Journalism \\
\hline Helena Ullstrand Design AB & Advertising \\
\hline Helsingborgs Dagblad & Journalism \\
\hline Hexatronic Fiberoptic AB & Electronics \\
\hline I-magé of pr AB & Advertising \\
\hline Ink n Art Produktionsbyrå AB & Graphic design \\
\hline Mittmedia AB & Media production \\
\hline Nordisk Film TV-Produktion AB & Media production \\
\hline Nyhetsbyrån Siren & Journalism \\
\hline Piteå-Tidningen & Journalism \\
\hline Print on demand Stockholm AB & Graphic design \\
\hline Profilskaparen & Graphic design \\
\hline Promotion i Boo & Advertising \\
\hline R.M. Electronic AB & Electronics \\
\hline Realtryck $A B$ & Graphic design \\
\hline Ricoh Sverige AB & Electronics \\
\hline Rodemreklam $\mathrm{AB}$ & Advertising \\
\hline Sib-Tryck Holding AB & Advertising \\
\hline StrieProfil AB & Advertising \\
\hline Sveriges Radio & Media production \\
\hline Sveriges Television & Media production \\
\hline Sydsvenskan & Journalism \\
\hline
\end{tabular}




\begin{tabular}{|l|l|}
\hline Sörmlands Media AB & Media production \\
\hline Tele2 Business AB & Telecom \\
\hline Teq Display & Advertising \\
\hline Tredje Statsmakten Media AB & Media production \\
\hline
\end{tabular}

Table 2: Media and communication companies in the customer register of the Swedish Prison and Probation Agency in 2018

We found that in 2018 at least 37 media companies were included in the customer register of Swedish prison production (see Table 2). In addition, the product catalogue from KrimProd, the unit responsible for organising production within the Swedish Prison and Probation Service, lists its own products (not those subcontracted and produced on demand), which are offered in the open market. This list includes media and communication products such as TV boxes, newspaper stands, acoustic panels, street stands, computer shells, envelopes and correspondence cards, among others (see Table 3).

\begin{tabular}{|r|r|c|c|c|}
\hline Year & Orders & $\begin{array}{l}\text { Televerket (public enterprise } \\
\text { for telecommunications) }\end{array}$ & Royal Mail & $\begin{array}{l}\% \text { of total tele- } \\
\text { communications }\end{array}$ \\
\hline 1970 & 2,150 & 211 & 52 & $12 \%$ \\
\hline 1971 & 1,800 & 103 & 50 & $12 \%$ \\
\hline 1972 & 1,700 & 72 & 42 & $7 \%$ \\
\hline 1973 & 1,700 & 79 & 37 & $7 \%$ \\
\hline 1974 & 1,700 & 75 & 22 & $6 \%$ \\
\hline
\end{tabular}

Table 3: Overview of the most important prison media work between 1970-1974. This information is taken from the order registers to the Swedish Prison and Probation Service

The client registry reveals only which companies have placed orders to the Prison and Probation Service and nothing about what kinds of products they have commissioned. In interviews, the production managers at the Kumla and Hall prisons told us of products for display and distribution, often for the advertising industry and for display media such as billboards, signs, and display stands. One example of such a product is the use of newsstands, which display newspapers and magazines common in most grocery stores and kiosks in Sweden and produced in the factory at Kumla Prison. In this way, the largely "invisible" work of incarcerated individuals is highly visible in public settings country-wide (Kaun and Stiernstedt 2020a).

Examples of contemporary prison media work exist beyond Sweden. In the US, the electronic waste recycling of broken computers and other media technologies in federal prisons, handled by the company UNICOR, has generated criticism due to the dangers of toxic e-waste (Jackson et al. 2006). In Finland, the Criminal Sanctions Agency (CSA) collaborated with the start-up company Vainu to provide a comprehensive database of businesses on a global level that employs artificial intelligence (AI) to predict the best business opportunities for its clients (Lehtiniemi and Ruckenstein forthcoming). To train Al, the start-up has worked with Amazon's Mechanical Turk, which hires online workers to classify content. The archetypal work conducted by platform workers is content categorisation - for example, determining whether a news article is about the company Apple or the fruit. Digital gig workers - in this case, incarcerated individuals - do what Al cannot do: interpret context and feed such data into a system, based on which machine learning will improve the algorithms. In the autumn of 2019, 
around 10 female prisoners were categorising the content of business publications at one Finnish prison. This work required no specific skills beyond the ability to read and very fundamental skills to use a laptop (Chen 2019; interview with Rasila). Similarly, incarcerated individuals conduct low-skilled, repetitive work at US prisons, contributing to the large-scale digitising projects of libraries and archives (Kaun and Stiernstedt 2021).

Another example of how prison labour feeds into contemporary media industries is found in software coding conducted by prisoners. Since 2010, The Last Mile programme ${ }^{3}$ has been training incarcerated individuals to code while serving their sentences. The Last Mile programme is offered in eleven prison facilities across California, Indiana, Kansas, and Oklahoma. It includes six months of software programming with eight hours of daily training (Last Mile Program 2020). In some facilities, such as San Quentin State Prison in California, where the Last Mile programme was first introduced, the incarcerated with coding skills are doing coding piecework for external partners. Their hourly pay differed significantly from their payments for other prison work assignments. For example, while an incarcerated coder earns up to USD17 per hour, his or her fellow inmates working in a kitchen or laundry section earn 13 to 80 cents per hour (Ear Hustle 2019; Sawyer 2017).

These examples reveal that production in the media and communications industries is an integral part of the prison system worldwide. Work tasks performed for the media and communications industry are, as with most prison labour, a form of routine manual labour; nevertheless, even though they play a marginal part in the media industries, they are not unimportant and comprise a fair share of the production in prisons.

\subsection{Consumption: Prison Media Tech}

Within the Swedish prison system, the so-called telecommunication surveillance of prisoners was implemented in the 1960s, but gained momentum in the 1970s. We argue that implementing telecommunications infrastructure for surveillance is an important part of the PMC. Not only are prisons one of the main customers of security solutions and technology, but much of the technological development of security technologies has been spurred by innovations first developed for a prison setting, while later finding their way into society (Kaun and Stiernstedt 2021).

At the same time, technologies for surveillance and other forms of so-called prison tech are not a national matter to the same extent as the Prison and Probation Service. Surveillance technology is a global industry, with a few companies dominating the market. In this section, we draw the contours of this market, the relations between international companies and the National Prison and Probation Service, and its role in the PMC

Different companies are involved in developing and selling technologies to prisons worldwide. First, there are the companies that deal mainly or exclusively with technologies for security, surveillance, and communication in prisons. Among these is USbased Stanley Security, one of the leading providers of electronic security systems to the corrections industry. Second, there are companies for which prisons are a secondary market or customer and that mainly supply other parts of repressive state apparatus (e.g., the military or police) with technologies for communication and surveillance; among these are Securitas, Attenti Group and MP Sec. Third, there are the big tech companies, such as Microsoft and GMI. For these, the prison industry is only a small segment of their customers.

${ }^{3}$ https://thelastmile.org/ (accessed 1 November 2021). 
Table 4 below shows all the global or international companies that were suppliers to the Swedish Prison and Probation Service in 2018 within the areas of technical security, communication technology, information security and individual security.

\begin{tabular}{|l|l|l|}
\hline Company name & Service & Company headquarters \\
\hline Supercom & Technical and physical security & Israel \\
\hline Attenti Group & Technical and physical security & Israel \\
\hline Stanley Security & Technical and physical security & USA \\
\hline Securitas & Technical and physical security & Sweden \\
\hline Siemens & Technical and physical security & Germany \\
\hline Nokas Security & Technical and physical security & Norway \\
\hline Caverion Security & Technical and physical security & Finland \\
\hline Ricoh & Communication technology & Japan \\
\hline Microsoft & Communication technology & USA \\
\hline CGI Group & Communication technology & Canada \\
\hline Secure State & Information security & Canada \\
\hline $\begin{array}{l}\text { Gemalto (Thales } \\
\text { Group) }\end{array}$ & Information security & The Netherlands \\
\hline MP Sec & Individual security & Sweden \\
\hline
\end{tabular}

Table 4: Overview over external services and products bought by the Swedish Prison and Probation Services in 2018, based on Freedom of Information Request

These companies deliver to prisons a range of media and communication technologies used for security and surveillance, such as electronic monitoring, surveillance cameras, offender monitoring systems, GPS-tracking and RF-bracelets; they also deliver more general communication solutions and digital infrastructure that is not specifically tailored for prison use, including information security systems and communication platforms. In 2018, Supercom, for example, landed a contract worth SEK 60 million for digitally monitoring offenders in Sweden's prisons, ${ }^{4}$ and Stanley Security the following year signed a multi-million SEK contract for surveillance camera equipment for Swedish prisons.

These deals are part of a public procurement proceeding in which companies can compete in a supposedly transparent process for contracts. However, there have been proven instances of corruption within these proceedings. As late as 2014, three managers within the Swedish Prison and Probation Service were sentenced to prison for corruption (such as taking bribes; SVT 2014). In 2012, the Swedish National Audit Office released a report that specifically defined the Prison and Probation Service as an area at risk of corruption and bribery (Riksrevisionen 2012). This led the Prison and

${ }^{4}$ 2017/S 077-148964, https://ted.europa.eu/udl?uri=TED:NOTICE:0532382019:TEXT:SV:HTML 
Probation Service to intensify its work to prevent instances of corruption. In 2017, it released a policy - their first ever - on this topic. Public procurement and the buying of goods and services is an area discussed in the policy paper, which instructs all parts of the authority to make annual risk assessments about corruption and bribery within its operations (Kriminalvården 2017).

This situation reveals that certain contracts and investments often rest on informal contacts and networks between state agencies and private enterprises, which is unsurprising given the structure of a PMC. Following the idea of the complex, corruption is, to some extent, a key element in the relationship between state agencies and commercial enterprises (Schiller and Phillips 1970). These relationships are fostered and maintained via the events and trade fairs that we attended and observed. Cornfeld (2018) calls these events "live theatres of technologies", where the latest technological innovations are presented and negotiated before their launches, hence underlining their importance for developing the security and surveillance industry beyond the prison complex.

\subsection{Development: Testbedding Emerging Technologies in Prisons}

The PMC also has wider significance for the media and communication industry due to the role that prisons play as testbeds for new technologies (Kaun and Stiernstedt $2020 a$; b). As with the importance of military-related technology developments, including cell phones, GPS and the Internet (Ledbetter 2011), technologies for surveillance and monitoring have at times been tested within a prison context or developed for situations of incarceration before they find their way to wider society. The ankle bracelet, originally inspired by a sci-fi cartoon (Gable and Gable 2016) and implemented in the 1970s for inmate surveillance and parole monitoring, was adapted for employee surveillance and morphed into Fitbits and other forms of digital self-tracking devices (Bernard 2019). Similarly, RFID scanning technology to automate inmate counts (provided by Guardian RFID, for example) has been remediated in scanners for Amazon warehouse workers (Delfanti 2019).

Technologies for automated voice recognition, so-called voiceprints, have been developed with prisons as testbeds. A precondition for using the telephone in many US prisons is that an inmate must agree to be recorded and that his or her conversation can be used for training voice recognition algorithms with a range of commercial applications (Joseph and Nathan 2019). Another example is electromagnetic contraband detectors, first developed in the health sector; in recent years, they have been adopted in corrections and further developed for this context. For example, they are now portable and can be moved easily within a prison facility. Recently, scanners have re-entered the tech sector, where they are used to monitor employees and guests to prevent business espionage helped by clandestine mobile phones or USB drives concealed on people entering and leaving business facilities (Kaun and Stiernstedt 2021).

These examples point to the fact that the PMC also entails aspects of innovation for new media and digital technologies in which the prison can play an important role as a testbed for media and communication companies. The relationship between prisons and these industries is not a one-way street where prisons are buyers and industry suppliers. It is rather the case that technologies move between different parts of the PMC, and that these moves are marked by iterations and changes that also help develop technologies for communication and societal control.

Beyond the test bedding of specific technologies, prisons are increasingly embedded in larger innovation projects based on collaborations with private companies. A prime example is the increasingly discussed ideas of "the smart prison" and "prisons 
without guards", which further strengthen the role of media and communication companies within the prison sector (Kaun and Stiernstedt 2020b). This is a global trend in which Asian countries have taken the lead. Hong Kong has, for example, opened the first operational smart prison. The general idea behind such initiatives is to integrate new digital technologies into the prison ecosystem, both for reasons of rehabilitation and normalisation and for surveillance and control, which are important aspects in the prison context.

To implement the idea of a smart prison, the discourse focuses on the prison as an area lagging and losing opportunities in terms of the digital transformation of society (Kaun and Stiernstedt 2021). To rehabilitate inmates and prepare them for life outside prison walls, digital technologies must be introduced within prisons. If digital is the new normal, then the principle of normality (of great importance in Scandinavian penology) must include digital technologies (van de Steene 2020). This includes initiatives in digital work for inmates, allowing them to work with coding and training Al. However, in the discourse on smart prisons, 'digital' is an elastic concept that includes allowing inmates to handle e-waste, to work with e-commerce and to manage incoming digital orders or take the role of customer support staff. It also includes introducing limited Internet access for inmates and allowing them to communicate with their family and friends not only via traditional landline telephony but also via video apps on specially designed inmate tablets.

All of this, of course, opens new business opportunities and increases the presence of media and communication companies within the prison realm. More debated, however, have been the aspects of security, control and surveillance in a smart prison. 'Robot-guards' equipped with microphones, loudspeakers, CCTV and infrared cameras, new Al-augmented CCTV camera systems with facial recognition, and wristbands with the ability to measure other biometrical data (such as heart rate) are part of the solutions and innovations implemented in the prison context (Leung 2019). These innovations are currently being tested at prisons in Asia and Europe to "enhance efficiency" (Dormehl 2019) within a prison and automate the work process to accomplish a "prison without guards" (Khair 2018).

The global discourse on smart prisons and the tropes of "radical innovation" within the correctional complex have also found traction within the Swedish context. These experiments have been organised as collaborations between the prison sector and state agencies, the research community and technology industry partners. At one of the industry expos we observed in this respect, the chief information technology officer at the Swedish Prison and Probation Service, Håkan Klarin, talked about a "triple helix" of academia, market partners and the Prison and Probation Service as the way towards digital transformation. In 2018, the idea of the "triple helix" was supported by the Swedish Innovation Agency, which approved a grant for a project to develop testbeds for radical innovation within the Prison and Probation Service based on the collaboration between industry, a public agency, and an academic partner. The project was described as an example of a turning point in public administration in Sweden and as a long-term investment working by "trial and error" with "smart technology" and "latest research" to develop and evaluate new technological solutions for the prison industry (Kaun and Stiernstedt 2021).

\section{Conclusion}

The notion of the PMC suggests that the relationship between prisons and media is not only established on a symbolic level in terms of media representations and ideological media texts about prison and incarceration, but also on the material level via 
industrial production in prison facilities. Prisons play a marginal yet significant role in the production of goods and services for the media and communication industry.

This material connection between the prison and media industries emerges as a combination of production, consumption and development that intertwines these sectors. Not only does work by prisoners produce communication technologies, but prisons are also large-scale consumers of technologies that make them an attractive field for a globally operating industry. In addition, prisons have functioned as sites for testing evolving technologies, as spaces in which privacy concerns are of less importance. We further argue that the intertwinement between the media and communication industry and the corrections sector increases over time. In particular, the extensive digitalisation of all levels of society, including the prison system, is a driving force of further entanglement. Digital media technologies are an increasingly integral part of the penal system while also being produced and tested in the prison context. This can be understood as a PMC in which formal and informal bonds are formed and interests aligned between the media and cultural industries, the state, and the prison system (with ties to neighbouring areas such as the military and police). One aspect of the PIC, discussed and theorised in much previous work, is therefore this PMC; here, the early work by Schiller and Phillips (1970) can aid our further analytical efforts in unpacking and unmasking these relationships between the media and communication industry and the prison system.

In the 1980s, de Sola Pool (1983) argued for the empowering potential of electronic communication technologies even before the Internet, social media and user-generated content were widely used and discussed. One of his main concerns was whether and how new electronic communication technologies emerging and evolving in legal grey zones can contribute to new freedom and empowerment through communication and how their freedom is linked with freedom of speech. He explored the policy and legal logics that evolve and envelop new technologies while emphasising the importance of electronic media technologies for the possibility of freedom.

Here, we are also concerned with questions of freedom through and with communication, albeit from a slightly different perspective. Our starting point is that the freedom of some people emerges in and through the unfreedom of others, both symbolically and materially. While media technologies enable many to have freedom through communication, media always also encompass captivity and the unfreedom of others who contribute to their production through forms of unfree labour. Incarcerated individuals worldwide who have contributed through their work to build media infrastructures, but who are subjected to constant surveillance by technology and, in that way, have contributed to technological developments, are an important part of de Sola Pool's terms 'electronic technologies of freedom'. At the same time, incarcerated individuals are often constrained in their access to and use of those very technologies.

De Sola Pool argues that media technologies are guaranteed different degrees of freedom by law, which has implications for someone's freedom of speech. His main concern is how regulation potentially constrains these freedoms when new electronic communication technologies emerge. What we have highlighted in this article is that media technologies should not only be thought of in terms of freedom but also in terms of captivity. Although media technologies allow freedom of speech and information, their infrastructure has been partly based on incarcerated individuals and captivity by people constrained from the possibilities to express themselves freely. The PMC is one telling example of the dialectic relationship highlighting the organisational entanglements between media industries and the corrections sector. 


\section{References}

Barton, Alana and Alyson Brown. 2015. Show me the Prison! The Development of Prison Tourism in the UK. Crime, Media, Culture 11 (3): 237-258.

Bernard, Andreas. 2019. The Triumph of Profiling: The Self in Digital Culture. Cambridge: Polity Press.

Blumstein, Alfred. 2011. Bringing Down the US Prison Population. The Prison Journal 91 (3): 12-26.

Brewer, Rose M. and Nancy A. Heitzeg. 2008. The Racialization of Crime and Punishment: Criminal Justice, Color-blind Racism, and the Political Economy of the Prison Industrial Complex. American Behavioral Scientist 51 (5): 625-644.

Brown, Michelle. 2009. The Culture of Punishment: Prison, Society, and Spectacle. New York: New York University Press.

Cheliotis, Leonidas K. 2010. The Ambivalent Consequences of Visibility: Crime and Prisons in the Mass Media. Crime, Media, Culture 6 (2): 169-184.

Chen, Angela. 2019. Inmates in Finland are Training Al as Part of Prison Labor. The Verge, 28 March. Accessed 29 November 2021. https://www.theverge.com/2019/3/28/18285572/prison-labor-finland-artificial-intelligence-data-taggingvainu

Cornfeld, Li. 2018. Babes in Tech Land: Expo Labor as Capitalist Technology's Erotic Body. Feminist Media Studies 18 (2): 205-220.

Davis, Angela. 2003. Are Prisons Obsolete? New York: Seven Stories Press.

Davis, Angela. 2000. Masked Racism: Reflections on the Prison Industrial Complex. Indigenous Law Bulletin 4 (27): 4-7.

Davis, Mike. 1995. Hell Factories in the Field: A Prison-Industrial Complex. The Nation 260 (7): 229-234.

de Sola Pool, Ithiel. 1983. Technologies of Freedom: On Free Speech in an Electronic Age. Cambridge: Harvard University Press.

Delfanti, Alessandro. 2019. Machinic Dispossession and Augmented Despotism: Digital Work in an Amazon Warehouse. New Media \& Society 23 (1): 39-55. DOI: https://doi.org/10.1177/1461444819891613

Delgoda, J. P. 1980. Prison Without Guards. International Journal of Offender Therapy and Comparative Criminology 24 (3): 244-248.

Dormehl, Luke. 2019. Hong Kong's Vision for a Smart Prison is a Full-Blown Orwellian Nightmare. Digital Trends, February 19. Accessed 5 December 2021. https://www.digitaltrends.com/cool-tech/hong-kong-smart-prison-tech/

Ear Hustle. 2019. Episode 32: Snack Money (Podcast). Accessed 29 November 2021. https://static1.squarespace.com/static/5bd0d552e8ba44146721bb3c/t/5d6934ea35b2ff00 01aa5ee1/1567175923643/Snack+Money+Transcript.pdf

Eriksson, Torsten. 1966. Kriminalvård på Anstalt [Corrections in the Institution]. In Kriminaliteten och Samhället [Crime and Society], edited by Jan Freese, 10-33. Stockholm: Bokförlaget Aldus/Bonniers.

Feldman, Lindsay Raisa. 2020. Anti-Heroes, Wildfire, and the Complex Visibility of Prison Labor. Crime, Media, Culture 16 (2): 221-238. https://doi.org/10.1177/1741659019865309

Fiddler, Michael. 2011. Projecting the Prison: The Depiction of the Uncanny in the Shawshank Redemption. Crime, Media, Culture 3 (2): 192-206.

Fuchs, Christian and Vincent Mosco. 2015. Marx and the Political Economy of the Media. Leiden: Brill.

Fulcher, Patrice. 2012. Hustle and Flow: Prison Privatisation Fueling the Prison Industrial Complex. Washburn Law Journal 2012 (3): 589-617.

Gable, Robert and Gable, Ralph. 2016. Remaking the Electronic Tracking of Offenders into a "Persuasive Technology". Journal of Technology in Human Services 34 (1): 13-31. doi:10.1080/15228835.2016.1138839 
Gilmore, Ruth. 2007. Golden Gulag: Prisons, Surplus, Crisis, and Opposition in Globalizing California. Berkeley, CA: University of California Press.

Goldberg, Eve, and Linda Evans. 2009. The Prison Industrial Complex and the Global Economy. Oakland, CA: PM Press.

Hartnett, Stephen, ed. 2011. Challenging the Prison-industrial Complex: Activism, Arts, and Educational Alternatives. Champaign, IL: University of Illinois Press.

Inverarity, James and David McCarthy. 1988. Punishment and Social Structure Revisited: Unemployment and Imprisonment in the United States, 1948-1984. The Sociological Quarterly 29 (2): 263-279.

Jackson, Anita Sarah, Aaron Shuman and Gopal Dayaneni. 2006. Toxic Sweatshops: How UNICOR Prison Recycling Harms Workers, Communities, the Environment, and the Recycling Industry. The Computer TakeBack Campaign, October. Center for Environmental Health: Prison Activist Resource Center, Silicon Valley Toxics Coalition. Accessed 30 November 2021. http://www.electronicstakeback.com/wp-content/uploads/ToxicSweatshops1.pdf

Joseph, George and Nathan, Debbie. 2019. Prisons Across the U.S. are Quietly Building Databases of Incarcerated People's Voice Prints. The Intercept, 30 January. Accessed 12 December 2021. https://theintercept.com/2019/01/30/prison-voice-prints-databasessecurus/

Kaun, Anne and Fredrik Stiernstedt. 2021. Prison Tech: Imagining the Prison as Lagging Behind and as a Test Bed for Technology Advancement. Communication, Culture \& Critique (online). DOI: https://doi.org/10.1093/ccc/tcab032

Kaun, Anne and Fredrik Stiernstedt. 2020a. Prison Media Work: From Manual Labor to the Work of Being Tracked. Media, Culture \& Society 42 (7-8): 1277-1292.

Kaun, Anne and Fredrik Stiernstedt. 2020b. Doing Time, the Smart Way? Temporalities of the Smart Prison. New Media \& Society 22 (9): 1580-1599.

Khair, Muhammad. 2018. A Prison Without Guards: Where Technology Enhances Operational Effectiveness. Singapore Prison Services, 6 July. Accessed 30 November 2021. https://www.mha.gov.sg/home-team-news/story/detail/a-prison-without-guards-wheretechnology-enhances-operational-effectiveness/

Kriminalvården. 2017. Policy för Kriminalvårdens Korruptionsförebyggande Arbete. Accessed 30 November 2021. https://www.kriminalvarden.se/globalassets/nyheter/policy-for-kriminalvardens-korruptionsforebyggande-arbete.pdf

Larsson, Bengt, Martin Letell and Håkan Thörn. 2012. Transformations of the Swedish Welfare State: Social Engineering, Governance and Governmentality. In Transformations of the Swedish Welfare State: From Social Engineering to Governance?, edited by Bengt Larsson, Martin Letell and Håkan Thörn, 3-22. Basingstoke: Palgrave Macmillan.

Last Mile Program. 2020. About Section (webpage). Accessed 30 November 2021. https://thelastmile.org/

Ledbetter, James. 2011. Unwarranted Influence: Dwight D. Eisenhower and the Military Industrial Complex. New Haven, CT: Yale University Press.

Lehtiniemi, Tuukka and Minna Ruckenstein. 2022 (forthcoming). Prisoners Training Al. In Everyday Automation, edited by Martin Berg, Deborah Lupton, Sarah Pink and Minna Ruckenstein, n.p. London: Routledge.

Leung, Christy. 2019. Robot Warders Check on Inmates as Hong Kong Tests 'Smart Prison' Devices to Step up Security Surveillance. South China Morning Post, 21 October. Accessed 30 November 2021. https://www.scmp.com/news/hong-kong/law-and-crime/article/3033791/robot-warders-check-inmates-hong-kong-tests-smart

Mancini, Matthew. 1996. One Dies, Get Another: Convict Leasing in the American South 1866-1928. Columbia, SC: University of South Carolina Press.

Mathiesen, Thomas. 2014. The Politics of Abolitionism Revisited. London: Routledge.

Novek, Eleanor. 2009. Mass Culture and the American Taste for Prisons. Peace Review: A Journal of Social Justice 21 (3): 376-384. 
Page, Allison and Laurie Ouellette. 2020. The Prison-Televisual Complex. International Journal of Cultural Studies 23 (1): 121-137.

PCARE. 2017. PCARE@ 10: Reflecting on a Decade of Prison Communication, Activism, Research, and Education, While Looking Ahead to New Challenges and Opportunities. Communication and Critical/Cultural Studies 14 (3): 288-310.

PCARE. 2007. Fighting the Prison-Industrial Complex: A Call to Communication and Cultural Studies Scholars to Change the World. Communication and Critical/Cultural Studies 4 (4): 402-420.

Pratt, John. 2008. Scandinavian Exceptionalism in an Era of Penal Excess: Part I: The Nature and Roots of Scandinavian Exceptionalism. The British Journal of Criminology 48 (2): 119-137.

Pratt, John and Anna Eriksson. 2012. In Defence of Scandinavian Exceptionalism. In Penal exceptionalism? Nordic Prison Policy and Practice, edited by Thomas Ugelvik and Jane Dullum, 235-260. London: Routledge.

Riksrevisionen. 2012. Kriminalvårdens Hantering av Anskaffningar av Byggnationer. [The Handling of Acquisition of new Buildings by the Prison and Probation Services]. Riksrevisionen [The Swedish National Audit Office]. Accessed 30 November 2021. https://www.riksrevisionen.se/rapporter/revisionsrapporter/2012/kriminalvarden-hanteringav-anskaffningar-av-byggnationer-lopande-granskning.html.

Rusche, Georg and Otto Kirchheimer. 2009/1939. Punishment and Social Structure. New Brunswick, NJ: Transaction Publishers.

Sawyer, Wendy. 2017. How Much do Incarcerated People Earn in Each State? Prison Policy Initiative (blog), 10 April. Accessed 30 November 2021. https://www.prisonpolicy.org/blog/2017/04/10/wages/.

Sawyer, Wendy and Peter Wagner. 2020. Mass Incarceration: The Whole Pie 2020 Prison Policy Initiative. Prison Policy Initiative Press Release (webpage), 24 March. https://www.prisonpolicy.org/reports/pie2020.html

Scharff Smith, Peter. 2012. A Critical Look at Scandinavian Exceptionalism. Welfare State theories, Penal Populism, and Prison Conditions in Denmark and Scandinavia. In Penal Exceptionalism? Nordic Prison Policy and Practice, edited by Thomas Ugelvik and Jane Dullum, 50-69. London: Routledge.

Schiller, Herbert and Joseph Dexter Phillips. 1970. Super-State: Readings in the Military-Industrial Complex. Urbana, IL: University of Illinois Press.

Schlosser, Eric.1998. The Prison-Industrial Complex. The Atlantic, 1 December, 51-74.

Smith, Earl and Angela Hattery. 2010. African American Men and the Prison Industrial Complex. Western Journal of Black Studies 34 (4): 387-398.

Smith, Earl and Angela Hattery. 2006. The Prison Industrial Complex. Sociation Today 4 (2): 1-28.

Sudbury, Julia. 2014. Global Lockdown: Race, Gender, and the Prison-Industrial Complex. London: Routledge.

SVT. 2014. Prison Sentence in Large-scale Bribe Scandal Within the Prison and Probation Services [Fängelsedom i Stor Muthärva inom Kriminalvården], 2 September. Accessed 29 November 2021. https://www.svt.se/nyheter/lokalt/stockholm/fangelsedom-i-kriminalvardsmal.

Thompson, Heather Ann. 2012. The Prison Industrial Complex: A Growth Industry in a Shrinking Economy. New Labor Forum 21 (3): 39-47.

van de Steene, Steven. 2020. The Principle of Normality: The New Normal is Digital - Applying the Principle of Normality in a Digital Society. Smart Corrections (website). Accessed 29 November 2021. https://www.smartcorrections.org/single-post/2020/03/16/The-principle-of-Normality-the-new-normal-is-digital---Applying-the-principle-of-Normality-in-a-digital-society 
von Hofer, Hanns. 1993. Fängelset: Uppkomst - Avskräckning - Inkapacitering: Tre Kriminologiska Studier [The Prison: its Birth - Deterrence - Incapacitation: Three Criminologigal Studies] (Dissertation). Stockholm: University of Stockholm.

Wacquant, Loic. 2002. Slavery to Mass Incarceration. New Left Review 13 (41): 41-60.

Wehr, Kevin and Elyshia Aseltine. 2013. Beyond the Prison Industrial Complex: Crime and Incarceration in the 21st century. London: Routledge.

Yousman, Bill. 2009. Inside Oz: Hyperviolence, Race and Class Nightmares, and the Engrossing Spectacle of Terror. Communication and Critical/Cultural Studies 6 (3): 265-284.

\section{About the Authors}

Fredrik Stiernstedt

is an associate professor in Media and Communication Studies at Södertörn University in Sweden. He studies media production, media and the labour market and the relationship between social class and media. With Anne Kaun, he is pursuing a project on the media history and media future of prisons.

\section{Anne Kaun}

is a professor in Media and Communication Studies at Södertörn University in Sweden. Her research interests include media activism, media practices, critical studies of algorithms, automation and artificial intelligence. With Fredrik Stiernstedt, she is pursuing a project on the media history and media future of prisons. 